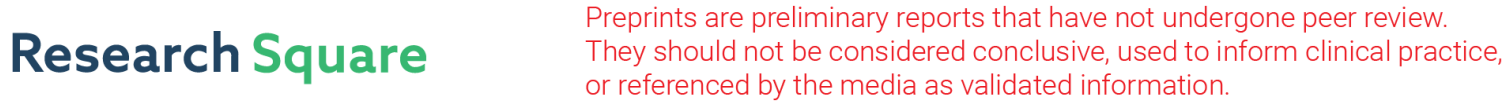 \\ Weakening of the Atlantic Niño variability under global warming
}

\section{Lander Crespo ( $\square$ lander.crespo@uib.no)}

University of Bergen and Bjerknes Centre for Climate Research https://orcid.org/0000-0003-1273-4303

\section{Physical Sciences - Article}

\section{Keywords:}

Posted Date: January 4th, 2022

DOl: https://doi.org/10.21203/rs.3.rs-829552/v1

License: (a) (i) This work is licensed under a Creative Commons Attribution 4.0 International License. Read Full License

Version of Record: A version of this preprint was published at Nature Climate Change on September 1st, 2022. See the published version at https://doi.org/10.1038/s41558-022-01453-y. 


\title{
Weakening of the Atlantic Niño variability under global warming
}

\author{
Lander R. Crespo ${ }^{1,2}$, Arthur Prigent ${ }^{3}$, Noel Keenlyside ${ }^{1,2}$, Shunya Koseki ${ }^{1,2}$, \\ Lea Svendsen ${ }^{1,2}$, Ingo Richter ${ }^{4}$, Emilia Sánchez-Gómez ${ }^{5}$ \\ ${ }^{1}$ Geophysical Institute, University of Bergen, Norway \\ ${ }^{2}$ Bjerknes Center for Climate Research, University of Bergen, Norway \\ ${ }^{3}$ GEOMAR, Kiel, Germany \\ ${ }^{4}$ Japan Agency for Marine-Earth Science and Technology, JAMSTEC, Japan \\ ${ }^{5}$ CERFACS, Toulouse, France
}

The Atlantic Niño is one of the most important tropical patterns of interannual climate variability, with major regional and global impacts. How global warming will influence the Atlantic Niño has been hardly explored, because of large climate model errors. We show for the first time that the state-of-the-art climate models robustly predict that equatorial Atlantic Niño variability will weaken in response to global warming. This is primarily because subsurface and surface temperature variations decouple as the upper equatorial Atlantic Ocean warms. The weakening is predicted by most $(>80 \%)$ models following the highest emission scenarios in the Coupled Model Intercomparison Project Phases 5 and 6 considered here. These indicate a reduction in variability by the end of the century of $12-17 \%$, and as much as $25 \%$ when accounting for model errors. Weaker Atlantic Niño variability will have major consequences for global climate and the skill of seasonal predictions.

The Atlantic Niño phenomenon exhibits many similarities to the stronger El Niño/Southern Oscillation ${ }^{1,2}$ (ENSO) in the Pacific. The eastern equatorial Atlantic is anomalously warm, surface trade winds relax and rainfall shifts equatorward during positive Atlantic Niño ${ }^{3-5}$ events. The sea surface temperature (SST) anomalies in the equatorial cold tongue can reach $1.5^{\circ} \mathrm{C}$ and thermocline $\left(20^{\circ} \mathrm{C}\right.$ isotherm) depth anomalies can exceed $30 \mathrm{~m}$ in boreal summer when the events peak. Opposite conditions are found during negative events. Coupled ocean-atmosphere interactions-Bjerknes positive and delayed negative feedbacks-similar to those in the Pacific can explain most Atlantic Nino variability, but other mechanisms can contribute substantially to equatorial SST anomalies ${ }^{6}$. The Atlantic Niño has 
significant impacts on the climate ${ }^{7-9}$ and marine biogeochemistry ${ }^{10,11}$ in the tropical

Atlantic sector, on ENSO ${ }^{12-16}$, and extra-tropical climate ${ }^{17-20}$.

Recent studies have shown a weakening of the Atlantic Niño variability in the last decades ${ }^{21-23}$. The changes in eastern equatorial Atlantic SST variability have been attributed to the combined effect of a weakening of the Bjerknes feedback ${ }^{24}$ (BF) and increased heat flux damping ${ }^{22,23}$, and to a basin-wide warming related to climate change ${ }^{24}$. These studies used observational and reanalysis datasets to investigate changes in the SST variability during the historical period.

Extensive analysis of the projections from the Coupled Model Intercomparison Project (CMIP) indicate that ENSO events will become stronger under global warming, but large uncertainties exist ${ }^{25-29}$. Large climate model biases in the tropical Atlantic sector ${ }^{30-33}$ have discouraged the climate community from carrying out similar in-depth assessment of climate change in the area. However, we will show that such biases do not preclude a more robust assessment of global warming impacts on Atlantic Niño variability than has been achieved in the Pacific.

\section{Weakened variability of the equatorial Atlantic SST}

To investigate how the SST variability in the eastern equatorial Atlantic will change under global warming, we use historical simulations and the future highest emission scenario simulations from the $\mathrm{CMIP}^{34}$ and $\mathrm{CMIP6}^{35}$ archive. The comparison between the historical (1950-99) and future scenario (2050-99) periods in the CMIP models shows that the SST variability in the eastern equatorial Atlantic sector in June-July-August (JJA) is reduced in the majority of the CMIP models (33 out of 40) (Fig. 1a and Table 1). The multi-model ensemble mean of CMIP5 (CMIP6) shows a reduction of the SST variability of $12 \%(17 \%)$ in the future scenario simulation with respect to the historical simulation (Table 1). The surface zonal winds in the western Atlantic sector also show a reduced future variability in May-June-July (MJJ) season in the CMIP5 and CMIP6 models with only 3 out of 40 models presenting an increased variability (Fig. 1d, Table 1). The ensemble mean of the standard deviation of the MJJ zonal wind anomalies (UAS hereafter) is reduced by $13 \%$ in CMIP5 and by $17 \%$ in CMIP6, which corresponds very well to the amplitude of the reduction in JJA SST variability (Table 1). The reduction of the zonal surface winds in the western equatorial Atlantic is consistent with a more stratified atmosphere in a future warmer climate ${ }^{36}$. 
Table 1. List of CMIP5 and CMIP6 models used in this study (first column). Standard deviation of the JJA ATL3-averaged SST anomalies and the MJJ ATL4-averaged UAS anomalies (second column) in brackets, during 1950-1999 and 2050-2099. The reduction is relative to the $1950-1999$ period. ENS is the multi-model ensemble mean of the CMIP5 and CMIP6. JJA ATL3-averaged SST change (fourth column), defined as the difference of the 2050-2099 mean minus the 1950-1999 mean.

80

\begin{tabular}{|c|c|c|c|c|c|}
\hline \multirow[b]{2}{*}{ No. } & \multirow[b]{2}{*}{ Models } & \multicolumn{3}{|c|}{$\begin{array}{c}\text { ATL } 3 \text { JJA SST Variability }\left[{ }^{\circ} \mathrm{C}\right] \\
\text { (ATL4 MJ UAS variability }\left[\mathrm{m} \cdot \mathrm{s}^{-1}\right] \text { ) }\end{array}$} & \multirow[t]{2}{*}{ ATL 3 JJA SST Change $[\mathrm{K}]$} \\
\hline & & $1950-1999$ & $2050-2099$ & Reduction $[\%]$ & \\
\hline 0 & ACCESS-CM2 & $0.54(1.41)$ & 0.38 (1.08) & $30(23)$ & 3.52 \\
\hline 1 & ACCESS-ESM1-5 & $0.68(1.21)$ & $0.53(0.87)$ & $22(28)$ & 3.14 \\
\hline 2 & BCC-CSM2-MR & $0.31(0.61)$ & $0.28(0.55)$ & $10(10)$ & 2.18 \\
\hline 3 & CAMS-CSMI-0 & $0.39(0.98)$ & $0.28(0.68)$ & $28(31)$ & 0.8 \\
\hline 4 & CanESM5 & $0.54(0.77)$ & $0.34(0.43)$ & $37(44)$ & 3.96 \\
\hline 5 & EC-Earth3 & $0.63(1.12)$ & $0.69(1.16)$ & $-10(-4)$ & 2.49 \\
\hline 6 & EC-Earth3-Veg & $0.65(1.05)$ & $0.60(1.09)$ & $8(-4)$ & 2.50 \\
\hline 7 & GFDL-ESM4 & $0.54(0.85)$ & $0.52(0.76)$ & $4(11)$ & 2.27 \\
\hline 8 & INM-CM4-8 & $0.34(0.57)$ & $0.26(0.49)$ & $24(14)$ & 2.23 \\
\hline 9 & INM-CM5-0 & $0.36(0.60)$ & $0.27(0.52)$ & $25(13)$ & 2.04 \\
\hline 10 & IPSL-CM6A-LR & $0.68(0.88)$ & $0.52(0.77)$ & $24(12)$ & 3.56 \\
\hline 11 & MIROC6 & $0.51(0.97)$ & $0.32(0.87)$ & $37(10)$ & 2.77 \\
\hline 12 & MPI-ESMI-2-HR & $0.56(0.88)$ & $0.35(0.60)$ & $38(32)$ & 1.81 \\
\hline 13 & MPI-ESMI-2-LR & $0.32(1.00)$ & $0.35(0.81)$ & $-9(19)$ & 1.68 \\
\hline 14 & MRI-ESM2-0 & $0.7(1.18)$ & $0.59(1.02)$ & $16(14)$ & 3.36 \\
\hline \multirow[t]{2}{*}{15} & NESM3 & $0.37(0.81)$ & $0.39(0.61)$ & $-5(21)$ & 2,34 \\
\hline & ENS & $\begin{aligned} 0.51 & \pm 0.14 \\
(0.93 & \pm 0.23)\end{aligned}$ & $\begin{array}{c}0.42 \pm 0.13 \\
(0.77 \pm 0.22)\end{array}$ & $\begin{array}{c}17 \pm 13 \\
(17 \pm 12)\end{array}$ & $2.70 \pm 0.58$ \\
\hline 16 & ACCESSI-0 & $0.41(0.72)$ & $0.29(0.68)$ & $29(6)$ & 3.07 \\
\hline 17 & ACCESS1-3 & $0.52(0.89)$ & $0.50(0.80)$ & $4(10)$ & 3.16 \\
\hline 18 & CMCC-CESM & $0.46(1.26)$ & $0.69(1.35)$ & $-50(-7)$ & 2.51 \\
\hline 19 & CMCC-CMS & $0.38(0.85)$ & $0.33(0.82)$ & $3(4)$ & 3.02 \\
\hline 20 & $\mathrm{CMCC}-\mathrm{CM}$ & $0.37(0.74)$ & $0.35(0.69)$ & $5(7)$ & 2.75 \\
\hline 21 & CNRM-CM5 & $0.23(0.88)$ & $0.22(0.84)$ & $5(5)$ & 2.11 \\
\hline 22 & CSIRO-MK3-6-0 & $0.46(0.56)$ & $0.33(0.34)$ & $28(39)$ & 2.59 \\
\hline 23 & GFDL-CM3 & $0.81(1.11)$ & $0.69(0.96)$ & $15(14)$ & 2.99 \\
\hline 24 & GFDL-ESM2M & $0.90(1.60)$ & $0.97(1.50)$ & $-8(6)$ & 2.36 \\
\hline 25 & GISS-E2-H-CC & $0.31(0.86)$ & $0.28(0.63)$ & $10(26)$ & 1.91 \\
\hline 26 & GISS-E2-H & $0.35(0.65)$ & $0.27(0.59)$ & $23(9$ & 2.16 \\
\hline 27 & GISS-E2-R-CC & $0.22(0.55)$ & $0.19(0.46)$ & $14(16)$ & 1.98 \\
\hline 28 & GISS-E2-R & $0.24(0.57)$ & $0.19(0.52)$ & $21(9)$ & 1.91 \\
\hline 29 & HadGEM2-CC & $0.82(1.18)$ & $0.60(1.01)$ & $27(14)$ & 3.41 \\
\hline 30 & IPSL-CM5A-LR & $0.48(0.55)$ & $0.45(0.52)$ & $6(5)$ & 3.83 \\
\hline 31 & IPSL-CM5A-MR & $0.44(0.57)$ & $0.38(0.48)$ & $14(16)$ & 3.70 \\
\hline 32 & IPSL-CM5B-LR & $0.31(1.31)$ & $0.32(1.03)$ & $-3(21)$ & 2.08 \\
\hline 33 & MIROC-ESM-CHEM & $0.33(0.42)$ & $0.26(0.35)$ & $21(17)$ & 3.27 \\
\hline 34 & MIROC-ESM & $0.37(0.42)$ & $0.27(0.35)$ & $27(17)$ & 3.25 \\
\hline 35 & MIROC5 & $0.63(1.31)$ & $0.41(0.82)$ & $35(37)$ & 3.10 \\
\hline 36 & MPI-ESM-LR & $0.43(0.86)$ & $0.34(0.64)$ & $21(26)$ & 2.80 \\
\hline 37 & MPI-ESM-MR & $0.48(0.77)$ & $0.36(0.69)$ & $25(10)$ & 2.76 \\
\hline 38 & MRI-CGCM3 & $0.52(0.98)$ & $0.4(0.95)$ & $23(3)$ & 2.43 \\
\hline \multirow[t]{2}{*}{39} & NorESM1-M & $0.43(1.13)$ & $0.49(0.99)$ & $-14(12)$ & 1.77 \\
\hline & ENS & $\begin{aligned} 0.45 & \pm 0.18 \\
(0.86 & \pm 0.31)\end{aligned}$ & $\begin{aligned} 0.40 & \pm 0.18 \\
(0.75 & \pm 0.29)\end{aligned}$ & $\begin{array}{r}12 \pm 18 \\
(13 \pm 10)\end{array}$ & $2.54 \pm 0.79$ \\
\hline
\end{tabular}

82 The reduction of the standard deviation in both SST and UAS is more pronounced 83 and localized in the ensemble mean of CMIP6 (Fig. 1c and f) than in CMIP5 (Fig 1b 84 and e). The weakening of the standard deviation of the MJJ zonal winds in the 85 western equatorial Atlantic is followed by a weakening of the eastern equatorial 86 Atlantic JJA SST variability in both CMIP5 (Fig. 1b and e) and CMIP6 (Fig. 1c and f) ensemble means, suggesting that the reduced wind variability may be the cause of 
88

a)
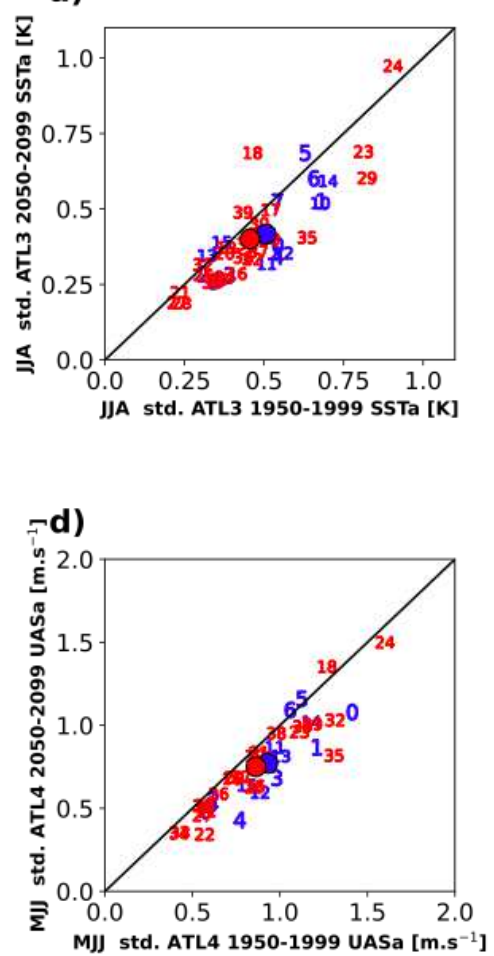

93 models.

the reduced SST variability. However, the linear regression between the two variables explains only $32 \%$ of the variance (Fig. S1). Consequently, there are other mechanisms that play an important role in the reduction of the standard deviation of the SST in the eastern equatorial Atlantic.

b)

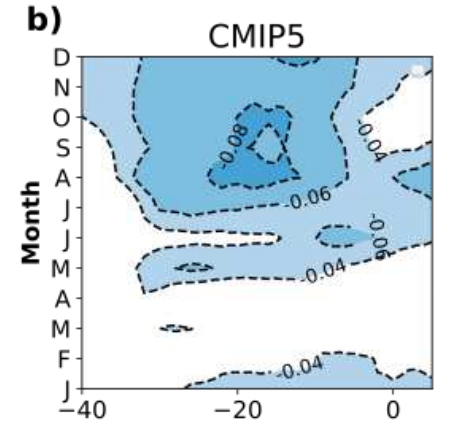

c)

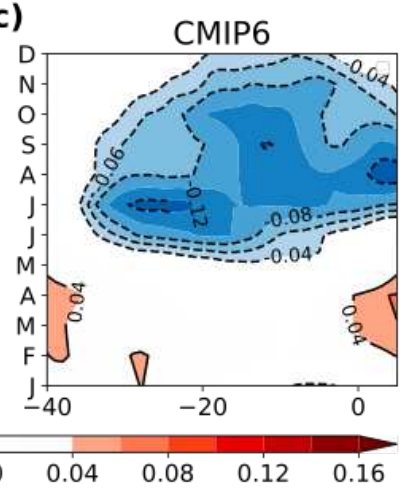

e)

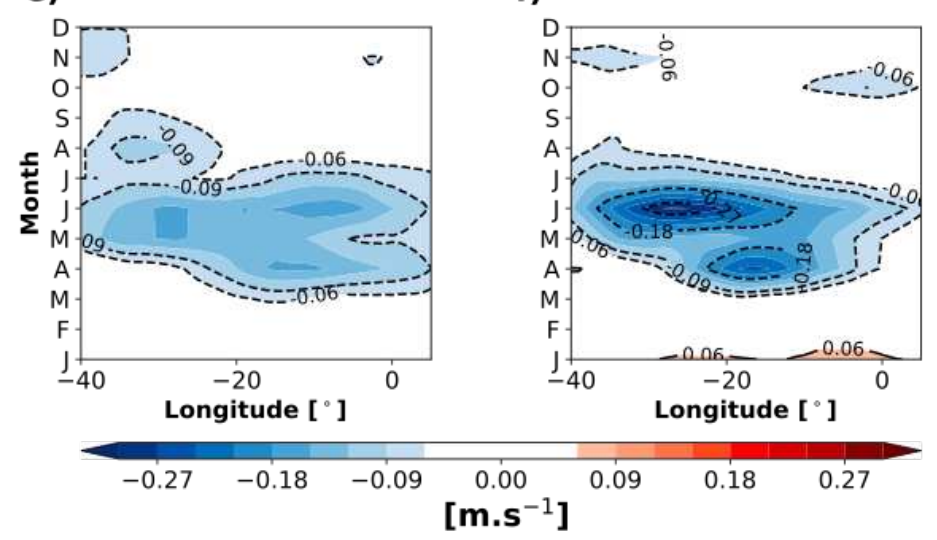

Figure 1. Weakening of the eastern equatorial Atlantic SST variability. (a) Scatter plot of the JJA average standard deviation of the SSTa for the historical period (1950-99) in the $x$ axis against the standard deviation of SSTa for the scenario period (2050-99) in the y axis. The black line represents the no-change line and is added for easier interpretation. Difference between the means of the 2050-2099 and the 1950-1999 periods standard deviation of the SST anomalies for the ensemble mean of CMIP5 (b) and CMIP6 (c) models, along the equator and averaged between $3^{\circ} \mathrm{S}$ and $3^{\circ} \mathrm{N}$. Same as (b) and (c) for the surface zonal wind anomalies of the CMIP5 (e) and CMIP6 (f) models, along the equator and averaged between $3^{\circ} \mathrm{S}$ and $3^{\circ} \mathrm{N}$. (d) Scatter plot of the MJJ average standard deviation of the UASa for the historical period (1950-99) in the $x$ axis against the standard deviation of UASa for the scenario period (2050-99) in the $y$ axis. The black line represents the no-change line and is added for easier interpretation. The blue (red) numbers correspond to the CMIP6 (CMIP5) models listed in Table 1. The blue (red) circle shows the ensemble mean of CMIP6 (CMIP5) 


\section{Weakened ocean-atmosphere coupling}

We explore the relative importance of the dynamical and thermodynamical

111 drivers of the future changes in the SST, through the BF components and the net

112 heat flux damping (Methods). The basin-wide weakening of the SST variability and

113 winds in the future scenario simulation might be related to a weakening of the BF.

114 The changes in variability in CMIP5 and CMIP6 are rather similar and therefore, we

115 will consider all CMIP models together in this section.

116 Both ensemble means of CMIP5 and CMIP6 models show a small change of 117 the first component of the BF (i.e. the linear regression of MJJ ATL4 zonal winds 118 anomalies on the JJA ATL3 SSTa). A majority of the CMIP models agrees on a 119 decrease of the 1 st component of the BF; 29 out of 40 models (Fig. 2a). The second 120 component of the $\mathrm{BF}$, the thermocline slope response to western equatorial wind 121 anomalies, shows a small reduction for CMIP models (Fig. 2b). The change in the

122 second BF component shows less inter-model agreement than the first component of 123 the BF with 26 out of 40 CMIP models showing a decrease of the second component 124 of the BF. The third component of the BF, that accounts for the local response of 125 SSTa to thermocline depth anomalies in the ATL3 region, shows the most consistent 126 changes; with 31 out of 40 CMIP models showing a reduction of the third BF 127 component. Both the CMIP5 and the CMIP6 multi-model ensemble means show a 128 reduction in the strength of this relation in the future climate simulations (Fig. 2f).

129 The change of the third BF component between historical and future 130 simulations is strongly related to the change in ATL3 JJA SST variability between the 131 two periods, with a explained variance of $61 \%$ when considering all CMIP models 132 (Fig. 2f). Contrastingly, the changes in components one and two of the BF explain 133 only little variance of the change in SST variability, namely $19 \%$ and $18 \%$, 134 respectively. Therefore, the reduced sensitivity of SST to local changes in 135 thermocline depth dominates the reduction of SST variability in the eastern equatorial 136 Atlantic in the future scenario. However, the majority of the CMIP models largely 137 underestimates the strength of this part of the feedback (Fig. 2c), a flaw already 138 present in CMIP5 models ${ }^{37}$ that still persists in the latest CMIP6 generation. 139 Therefore, the CMIP models might underestimate the future reduction of SST 140 variability. 
a)

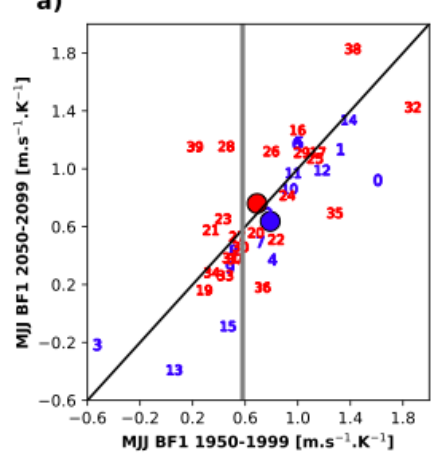

$$
\text { d) }
$$

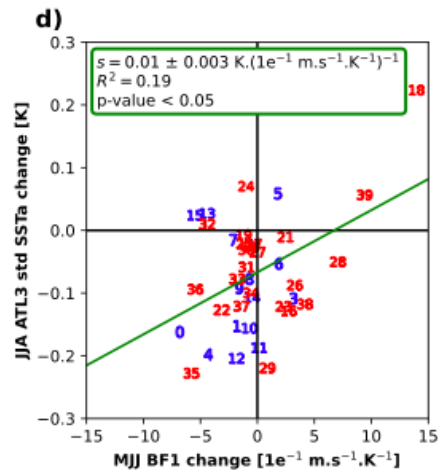

b)

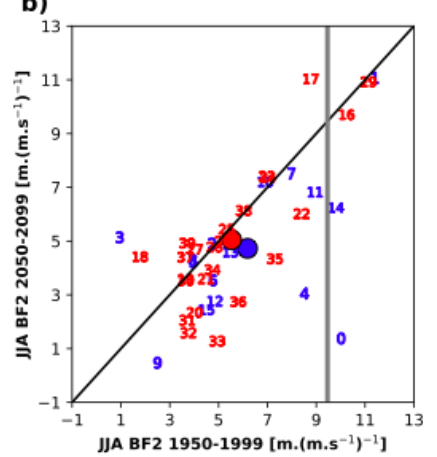

e)

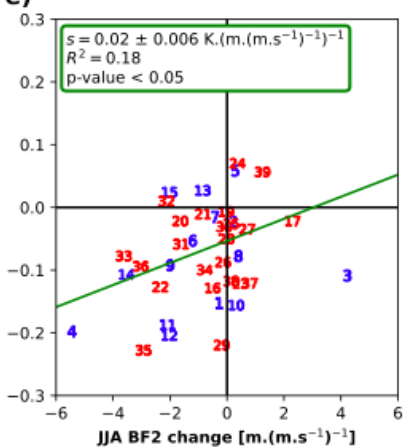

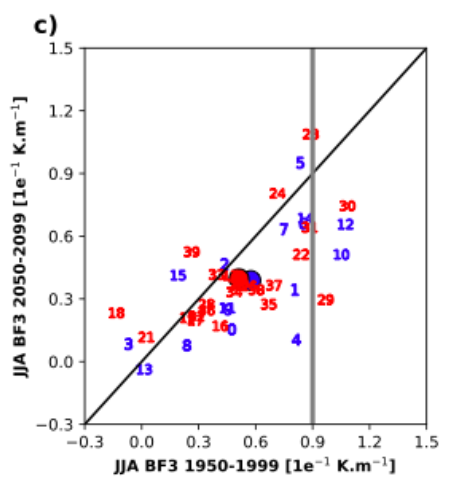

f)

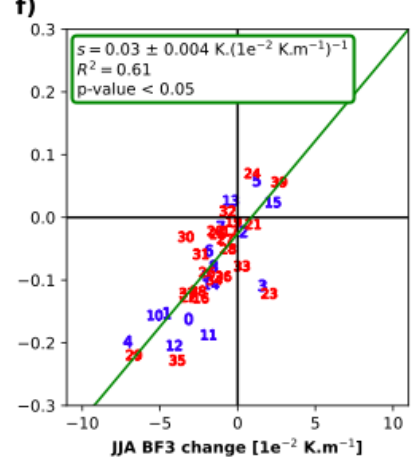

Figure 2. Dynamical drivers of the weakening of the SST variability. Changes between the historical and future scenario in the strength of the Bjerknes feedback (BF) components. (a) $1^{\text {st }}$ component of the BF is the linear regression of ATL4 MJJ UAS anomalies against the JJA ATL3 SSTa. (b) $2^{\text {nd }}$ component of the BF as the linear regression of ATL4 JJA UAS anomalies on the thermocline slope depth anomalies (aka z20 in Atl3 minus z20 in Atl4). (c) $3^{\text {rd }}$ component of BF computed as the linear regression of ATL3 JJA SSTa onto the JJA ATL3 Z20 anomalies. The blue and red dots are the ensemble mean of the CMIP6 and CMIP5 ensemble, respectively. Linear regression between the change in JJA SSTa variance and the change in BF components ( $d, e, f)$. The change here is defined as the difference of the mean of the scenario period (2050-99) minus the mean of the historical period (1950-99). The vertical grey lines represent an estimation of the three components of the BF $(a, b$ and $c)$ from observation and reanalysis datasets.

\section{Future mean changes of the tropical Atlantic SST}

The strength of the 3rd component of Bjerknes Feedback is linked to the strength of climatological upwelling and vertical temperature stratification ${ }^{38}$. In particular, a weaker feedback can result from the weaker upwelling of relatively warmer subsurface waters. Despite a large intermodel spread, the SST change between historical and future scenario simulations shows a robust warming of the equatorial Atlantic cold tongue consistent with weakening of this component of the 
163 BF (Table 1). The future scenario simulations of CMIP5 and CMIP6 models present a 164 warming of the JJA season in the eastern equatorial Atlantic of $2.54 \pm 0.79^{\circ} \mathrm{C}$ and $1652.70 \pm 0.58^{\circ} \mathrm{C}$, respectively. The multimodel ensemble mean of the CMIP5 and 166 CMIP6 models show a warming of $2^{\circ} \mathrm{C}$ to $3^{\circ} \mathrm{C}$ in the tropical Atlantic sector between 167 the historical and the future scenario simulation (Fig. 3a,b). The spatial patterns of 168 the future warming rate in the multimodel ensemble mean of both CMIPs are rather 169 similar and show a strong zonally homogeneous warming along the equatorial band. 170 The surface trade winds are projected to weaken in most of the tropical Atlantic in 171 CMIP5, coinciding with the warming pattern. In the CMIP6 ensemble mean, the 172 weakening of the surface trade winds is confined to the eastern equatorial Atlantic 173 and north of $10^{\circ} \mathrm{N}$ (Fig. 3a,b). Weaker equatorial trade winds will weaken equatorial 174 upwelling, and thereby contribute to a weaker 3rd component of the BF.

175 The vertical section of the difference between future scenario and historical of 176 the equatorial Atlantic ocean temperature clearly shows a stronger warming of the 177 upper ocean, going from the surface down to about 50 meters in the eastern 178 equatorial Atlantic, and 70 meters in the western equatorial Atlantic in the CMIP5 179 ensemble mean (Fig. 3c). The warming in the eastern equatorial Atlantic is even 180 more pronounced in the CMIP6 ensemble mean (Fig. 3d). The warming of the upper 181 levels is rather zonally homogeneous in both CMIP5 and CMIP6. However, this is not 182 the case for the deeper levels where the eastern equatorial Atlantic is warming faster 183 than the western side of the basin; this warming pattern could be related to changes 184 in oceanic circulation associated with the subtropical cells and $\mathrm{AMOC}^{39}$. The strong 185 warming of the upper levels in the ensemble mean of both CMIP generations leads 186 to a deeper thermocline in the future scenario (Fig. 3c,d). As the thermocline gets 187 deeper the coupling between the thermocline and the SST gets weaker, because the 188 stratification at the base of the mixed layer becomes weaker. In other words, the 189 variability in the SST is less sensitive to the variability of the thermocline, in 190 agreement with the previously shown weakening of the third component of the 191 Bjerknes feedback (Fig. 2c). 
a)

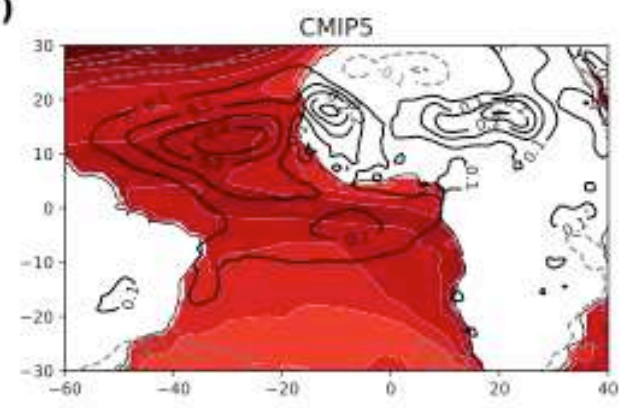

c)

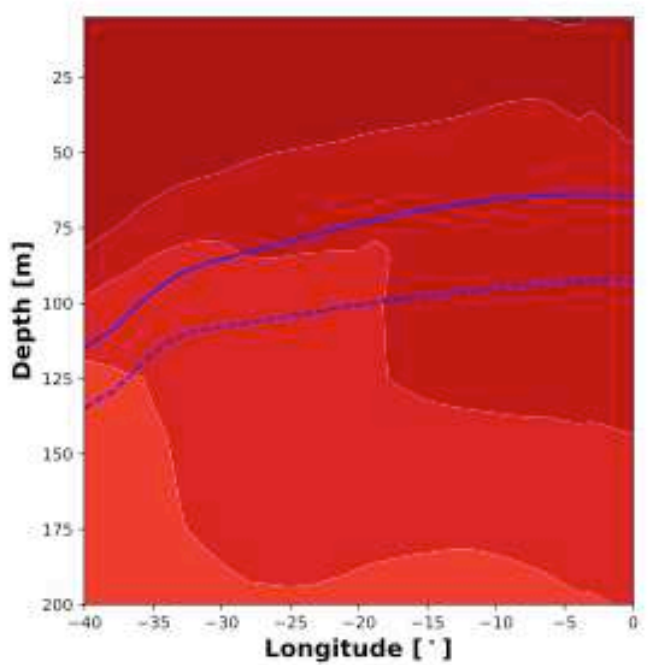

b)

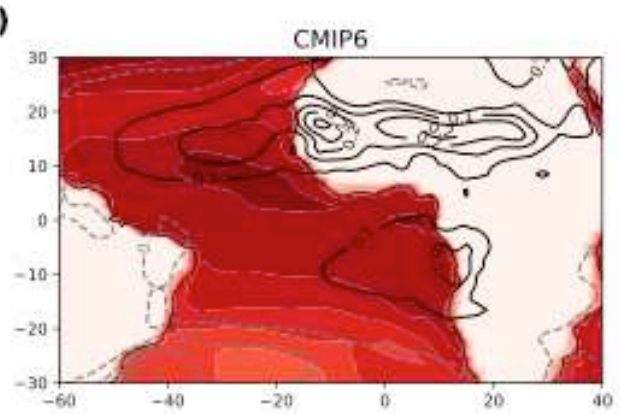

d)

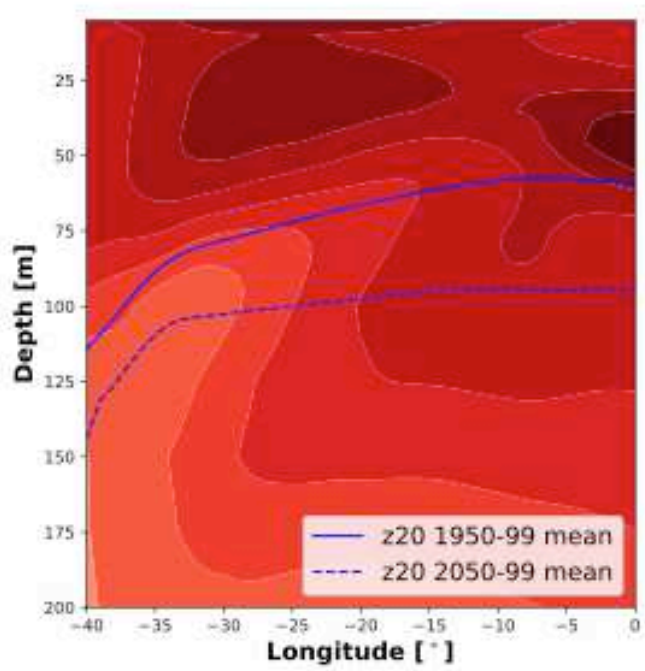

Figure 3. Mean state changes in the equatorial Atlantic. (Top row) Difference between future scenario and historical simulations of SST (in shading) and zonal surface winds (in contours) for the multi-model ensemble means of (a) CMIP5 and (b) CMIP6. The dashed (solid) contours show negative (positive) zonal winds which implies a strengthening (weakening) of the prevalent trade winds. The units are ${ }^{\circ} \mathrm{C}$ and $\mathrm{m} / \mathrm{s} /$ for SST and for zonal winds, respectively. (Bottom row) Vertical section of the difference in ocean temperature between future scenario and historical simulations for (c) CMIP5 and (d) CMIP6 multi-model ensemble means for June-July-August average. The blue solid (dashed) line represents the depth of the $20^{\circ} \mathrm{C}$ isotherm, for the climatological mean of the historical (future scenario) period. The temperature has been latitudinally averaged from $3^{\circ} \mathrm{S}$ to $3^{\circ} \mathrm{N}$. The periods taken for the historical and the scenario simulations are 1950-99 and 2050-99, respectively.

\section{Impact of model biases}

Coupled general circulation models show large biases in the tropical Atlantic

208 region $^{30-33,40,41}$, and in particular, a warm SST bias in JJA in the eastern equatorial 209 Atlantic, where projected changes in SST variability are largest. We explore to what 210 extent our findings are affected by the model biases in the region. We find that the 
211 models with smaller bias have a stronger reduction of the SST variability (Fig. 4a), a 212 stronger reduction of the third component of the Bjerknes feedback (i.e. the 213 thermocline feedback) (Fig. 4b) and a larger SST change between future scenario 214 and historical (Fig. 4c). This is consistent with a previous study using different 215 versions of the same climate model ${ }^{42}$. Therefore, biases in the models seem to 216 suppress the reduction of the SST variability in a future warmer climate through a 217 reduction of the weakening of the thermocline feedback. In light of these 218 relationships, the reduction of future SST variability might indeed be larger than 219 shown in this study if the models were unbiased and the reduction of the thermocline 220 feedback would be better captured.

221 The reduction of the SST variability could also be affected by changes in the 222 thermodynamical coupling between the ocean and the atmosphere. However, we 223 find that in the CMIP models the thermodynamical mechanism is not relevant for 224 explaining the change in the SST variance between the future climate and the 225 historical climate periods (Fig. S3). 

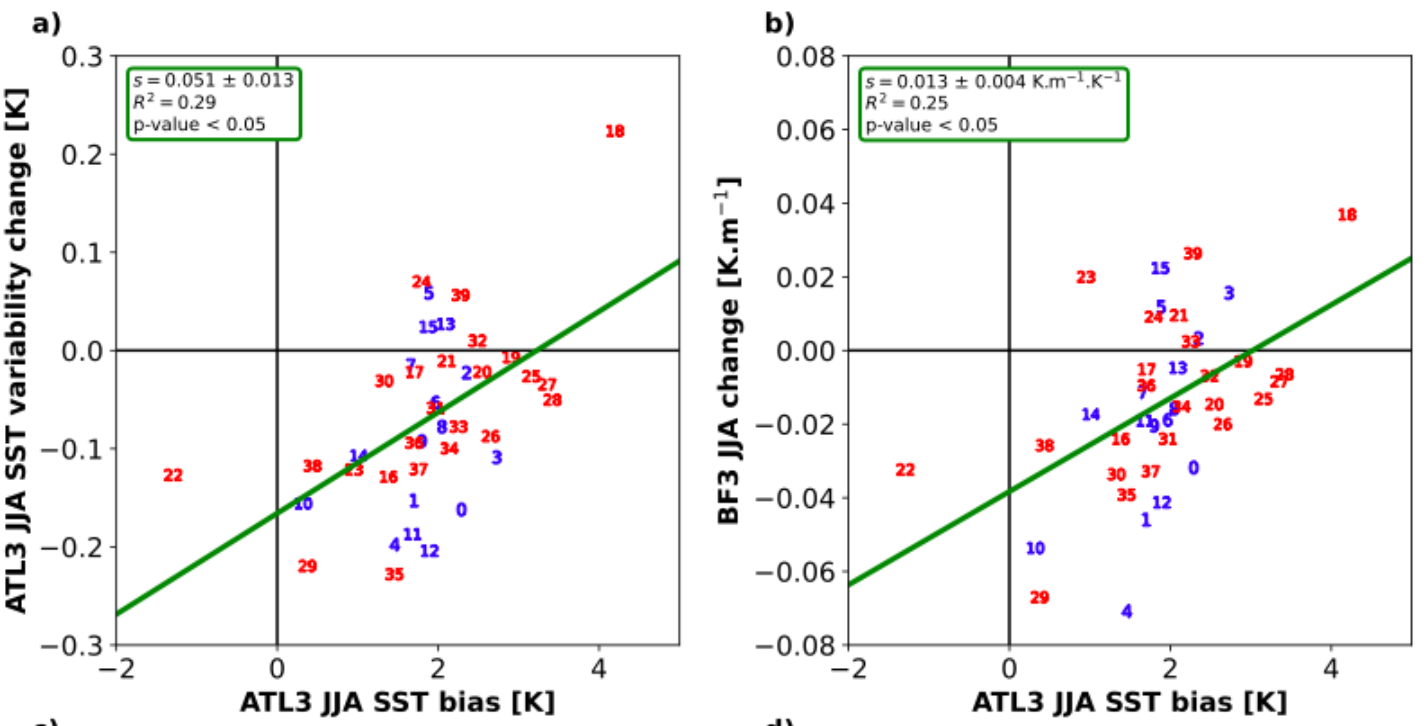

c)
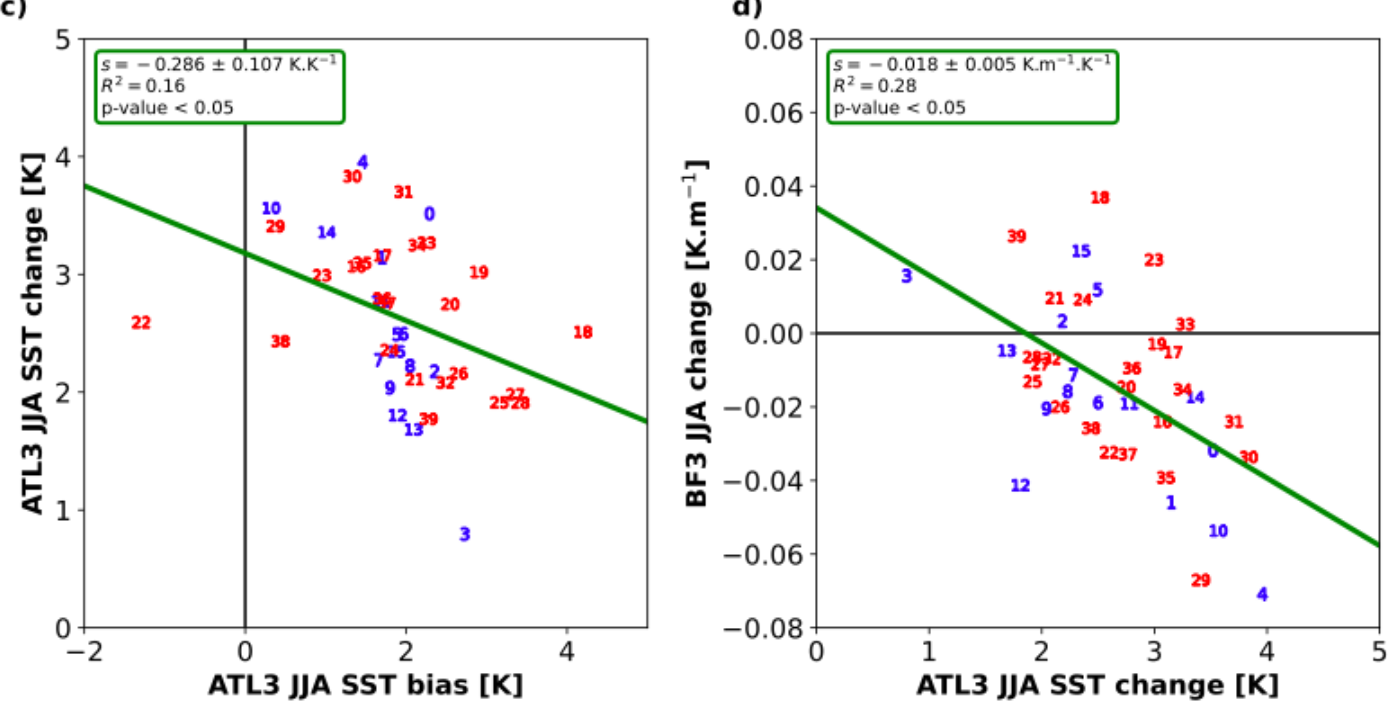

Figure 4. Impact of model biases. (a) Scatter plot of the JJA ATL3-averaged SST bias and SST variability change. The SST bias is estimated as the difference between model SST and Hadl-SST over the period 1950-1999. (b) Scatter plot of JJA ATL3-averaged SST bias and BF3 change. (c) Scatter plot of JJA ATL3-averaged SST bias and mean SST change. (d) Scatter plot of JJA ATL3-averaged mean SST change and BF3 change. The change here is defined as the difference of the mean of the scenario period (2050-99) minus the mean of the historical period (1950-99).

\section{Concluding remarks}

We show that the eastern equatorial Atlantic SST variability is projected to weaken in a future warmer climate when comparing historical and future scenario simulations of the CMIP5 and CMIP6 models. The projected future weakening of the 
240 SST variability in the CMIP models is strongly related to changes in the Bjerknes

241 feedback. Particularly, the weakening of the third component of the Bjerknes

242 feedback, the so-called thermocline feedback, explains up to $61 \%$ of the change in

243 the SST variance. We find that in a warmer future climate the upper-layer of the

244 ocean will become deeper and equatorial trade winds weaken. This together leads to

245 a weakening of the thermocline feedback, because the thermocline decouples from

246 the SST variability. This mechanism is remarkably different to the driving

247 mechanisms of climate change in the equatorial Pacific, where the changes in the

248 zonal SST gradient under greenhouse forcing are most relevant ${ }^{43-45}$. However, in

249 contrast to our findings in the Atlantic, the models in the Pacific show little agreement

250 on the sign of the change in SST gradient ${ }^{45}$.

The future weakening of the SST could be interpreted as an amplification of 253 the already observed weakening in the recent decades that has been attributed to a 254 weakening of the Bjerknes feedback and a stronger thermal damping ${ }^{21-23}$. The role of 255 the Bjerknes feedback in the CMIP models is key for the weakening in SST 256 variability. However, the CMIP models do not show any significant relationship 257 between changes in the heat fluxes and changes in the SST variability. Furthermore, 258 the biases present in the CMIP models affect the amplitude of the SST variability. 259 The weakening of the SST variability in the future is stronger in the models with less 260 SST biases. Reducing the biases in the models should increase the reliability of the 261 climate projections in the tropical Atlantic sector and greatly improve our assessment 262 of climate change in the region.

\section{Methods}

Data. We use monthly mean model outputs obtained from the two latest CMIP international exercises: CMIP5 ${ }^{34}$ and $C M I P 6^{35}$. We use the following fields from the

268 CMIP models: sea surface temperature (SST), zonal surface wind anomalies

269 (UASa), surface heat fluxes and the ocean potential temperature to derive the depth

270 of the $20^{\circ} \mathrm{C}$ isotherm depth to use it as a proxy of the thermocline depth ( $z 20$

271 hereafter). In addition, we use the SST from the Optimum Interpolation SST analysis

272 version $2\left(\mathrm{OI}_{-S S T}{ }^{46}\right)$ available at $1^{\circ}$ by $1^{\circ}$ horizontal resolution for the period $1981 / 12$

273 to 2019/12; the temperature from Ocean Reanalysis System Version 4 (ORA-S4 ${ }^{47}$ )

274 from the European Centre for Medium-range Weather forecast (ECMWF) available at 
$2751^{\circ}$ by $1^{\circ}$ horizontal resolution for the period $1958 / 01$ to $2017 / 12$; and the zonal wind

276 speed from ECMWF Re-Analysis (ERA)-interim ${ }^{48}$ available at $0.5^{\circ}$ by $0.5^{\circ}$ horizontal

277 resolution for the period $1979 / 01$ to $2018 / 12$ were used to estimate the three

278 components of the Bjerknes feedback over the period 1982/01-2017/12. We

279 investigate future climate changes in the equatorial Atlantic using the highest

280 emissions future scenarios, rcp85 and ssp585, for CMIP5 and CMIP6, respectively.

281 The climate models used in this study are listed in Table 1. All model data has been

282 interpolated to a common horizontal $1^{\circ} \times 1^{\circ}$ grid.

283 Statistical metrics. We use the standard deviation of the June-July-August (JJA)

284 SST anomalies (SSTa) and the May-June-July (MJJ) zonal surface wind anomalies

285 (UASa) as metrics to investigate the changes in variability between the simulated

286 historical and future climate periods. The season JJA (MJJ) is chosen for the SST

287 (UAS) variability as it is the season of largest SST (UAS) variability in CMIP5 and

288 CMIP6 models. For this analysis we use the 50-yr periods January 1950 to

289 December 1999 and January 2050 to December 2099 for the historical and scenario

290 simulations, respectively. We calculate the monthly anomalies by subtracting the

291 seasonal cycle evaluated on each time period. We remove all linear trends prior to 292 this analysis.

293 Quantification of dynamical ocean-atmosphere feedbacks. We compute the 294 three components of the Bjerknes feedback that involve SST, thermocline depth and 295 zonal surface winds to explore the potential dynamical drivers of the future changes 296 in the SST variability ${ }^{49}$. The three components of the Bjerknes feedback are 297 estimated through linear regression of (1) western equatorial Atlantic $\left(3^{\circ} \mathrm{S}-3^{\circ} \mathrm{N}\right.$, $29840^{\circ} \mathrm{W}-20^{\circ} ;$ ATL4) zonal wind stress anomalies upon eastern equatorial Atlantic $\left(3^{\circ} \mathrm{S}-\right.$ $2993^{\circ} \mathrm{N}, 20^{\circ} \mathrm{W}-0^{\circ} \mathrm{N}$; ATL3), (2) equatorial thermocline slope anomalies regressed onto 300 ATL4 zonal wind stress anomalies and (3) SSTa in ATL3 upon thermocline depth 301 anomalies in ATL3. The equatorial thermocline slope is computed as the difference 302 between the mean z20 in ATL3 and ATL4.

\section{Acknowledgements}

305 The CMIP6 data can be found at https://esgf-data.dkrz.de/search/cmip6-dkrz/. The 306 CMIP5 data can be found at https://esgf-node.IInl.gov/search/cmip5/. This study was 307 partially supported by the German Federal Ministry of Education and Research as 308 part of the BANINO project (03F0795A). The work was supported by the $\mathrm{H} 2020$ 309 TRIATLAS project (grant 817578) and the ERC STERCP project (grant 648982). We 
310 also acknowledge Norwegian national computing and storage resources provided by

311 UNINETT Sigma2 AS (NN9039K, NS9039K, NN9385K, NS9207k).

Author contributions:

314 LC, NK, SK, IR, LS and ES designed the research. LC and AP performed all the 315 analysis and prepared the figures. LC and AP wrote the first draft. All authors read 316 and commented on the text.

\section{Competing interests:}

319 No authors have any competing interests.

Watanabe, M. et al. Uncertainty in the ENSO amplitude change from the past to the future. Geophys. Res. Lett. 39, L20703 (2012).

\section{References}

1. McPhaden, M. J., Zebiak, S. E. \& Glantz, M. H. ENSO as an integrating concept in Earth science. Science 314, 1740-1745 (2006).

2. Timmermann, A. et al. El Niño-Southern Oscillation complexity. Nature, 559(7715), 535-545 (2018).

3. Keenlyside, N. \& Latif, M. Understanding equatorial Atlantic interannual variability. J Climate 20(1):131-142. https ://doi.org/10.1175/jcli3 992.1 (2007).

4. Lübbecke, J et al. Equatorial Atlantic variability—modes, mechanisms, and global teleconnections. Wiley Interdiscip Rev Climate Change 9(4):1-18. a\%3e2.0.co;2 (1993).

344 6. Lübbecke, J. et al. Equatorial Atlantic variability-Modes, mechanisms, and global

345 teleconnections. WIREs Clim Change 9:e527. https://doi.org/10.1002/wcc.527 346 (2018). 
348 7. Hirst, A. \& Hastenrath, S. Atmosphere-ocean mechanisms of climate anomalies in

349 the Angola-Tropical Atlantic sector. J Phys Oceanogr 13(7):1146-1157. https

350 ://doi.org/10.1175/1520-0485(1983)013\%3c114 6:aomoc a\%3e2.0.co;2 (1983).

352 8. Nobre, P. \& Shukla, J. Variations of SST, wind stress and rainfall over the tropical

353 Atlantic and South America. J Climate 9(May):2464-2479.

354 https://doi.org/10.1175/1520-0442(1996)009\%3c246 4 (1996).

355

356 9. Gu, G, \& Adler, R. Seasonal evolution and variability associated with the West 357 African monsoon system. J Clim 17(17):3364-3377 (2004).

10. Boyd, A., Tauntonclark, J. \& Oberholster, G. Spatial features of the near-surface and midwater circulation patterns off western and southern South Africa and their role in the life histories of various commercially fished species. S. Afr. J. Mar. Sci. 12 , 189206 (1992).

11. Chenillat, F. et al. How do climate modes shape the chlorophyll-a interannual variability in the tropical Atlantic? Geophysical Research Letters,

48, e2021GL093769. https://doi.org/10.1029/2021GL093769 (2021). (2009).

13. Ding, H., Keenlyside, N. \& Latif, M. Impact of the Equatorial Atlantic on the El Niño Southern oscillation. Clim. Dynam. 38, 1965-1972 (2012). Processes in the Pacific La Niña onset triggered by the Atlantic Niño. Clim. Dyn. 44, 115-131, https://doi.org/10.1007/s00382-014-2354-7 (2015). prediction. Geophys. Res. Lett. 42, 6802-6810 (2015). 
16. Exarchou, E., Ortega, P., Rodríguez-Fonseca, B. et al. Impact of equatorial

383 Atlantic variability on ENSO predictive skill. Nat Commun 12, 1612 (2021). https://doi.org/10.1038/s41467-021-21857-2

17. García-Serrano, J., Losada, T., Rodríguez-Fonseca, B., \& Polo, I. (2008). Tropical Atlantic variability modes (1979-2002). Part II: Time-evolving atmospheric circulation related to SST-forced tropical convection. Journal of Climate, 21(24), 6476-6497.

18. Haarsma, R. J., \& Hazeleger, W. (2007). Extratropical atmospheric response to equatorial Atlantic cold tongue anomalies. Journal of Climate, 20, 2076-2091. https://doi.org/10.1175/JCLI4130.1

19. Losada, T., Rodríguez-Fonseca, B., \& Kucharski, F. (2012). Tropical influence on the summer Mediterranean climate. Atmospheric Science Letters, 13(1), 36-42.

20. Mohino, E., \& Losada, T. (2015). Impacts of the Atlantic equatorial mode in a warmer climate. Climate Dynamics, 45(7-8), 2255-2271.

21. Tokinaga $\mathrm{H}$, Xie SP (2011) Weakening of the equatorial Atlantic cold tongue over the past six decades. Nat Geosci 4(4):222-226. https://doi.org/10.1038/ngeo1078

22. Prigent, A., Lübbecke, J., Bayr, T., Latif, M., \& Wengel, C. (2020). Weakened SST variability in the tropical Atlantic Ocean since 2000. Climate Dynamics, 54(5-6), 2731-2744. https://doi.org/10.1007/s00382-020-05138-0

23. Silva, P., Wainer, I. \& Khodri, M. Changes in the equatorial mode of the Tropical Atlantic in terms of the Bjerknes Feedback Index. Clim Dyn (2021). https://doi.org/10.1007/s00382-021-05627-w variability in terms of the Bjerknes stability index. J. Clim. 27, 2577-2587 (2014).

25. Collins, M. et al. The impact of global warming on the tropical Pacific Ocean and 
418 26. DiNezio, P. N. et al. Mean climate controls on the simulated response of ENSO

419 to increasing greenhouse gases. J. Clim. 25, 7399-7420 (2012).

421 27. Kim, T. et al. Response of El Niño sea surface temperature variability to 422 greenhouse warming. Nature Clim. Change 4, 786-790 (2014).

28. Cai, W. et al. Increasing frequency of extreme El Niño events due to greenhouse warming. Nature Clim. Change 4, 111-116 (2014).

29. Cai, W. et al. More frequent extreme La Niña events under greenhouse warming. Nature Clim. Change 5, 132-137 (2015).

30. Li, G. \& Xie, S. P. Origins of tropical-wide SST biases in CMIP multi-model ensembles. Geophys. Res. Lett. 39, L22703 (2012).

31. Richter, I., Xie, S. P., Behera, S. K., Doi, T. \& Masumoto, Y. Equatorial Atlantic variability and its relation to mean state biases in CMIP5. Clim. Dyn. 42, 171-188 (2014) and their relation to surface wind stress and terrestrial precipitation. Clim. Dyn. 38, 985-1001 (2012).

33. Richter, I., Tokinaga, H. An overview of the performance of CMIP6 models in the tropical Atlantic: mean state, variability, and remote impacts. Clim Dyn 55, 2579 2601 (2020). https://doi.org/10.1007/s00382-020-05409-w

35. Eyring, V., et al. (2015). Overview of the Coupled Model Intercomparison Project 450 Phase 6 (CMIP6) experimental design and organisation. Geoscientific Model 451 Development, 8(12), 10, 539-10,583 https://doi.org/10.5194/gmdd-8-10539-2015 
453 36. Maloney, E. D., and S.-P. Xie (2013), Sensitivity of tropical intraseasonal 454 variability to the pattern of climate warming,J. Adv. Model. Earth Syst., 5, 32-47, 455 doi:10.1029/2012MS000171.

37. Deppenmeier, AL., Haarsma, R.J. \& Hazeleger, W. The Bjerknes feedback in the tropical Atlantic in CMIP5 models. Clim Dyn 47, 2691-2707 (2016). https://doi.org/10.1007/s00382-016-2992-z

460

38. Ding, H., Keenlyside, N., Latif, M., Park, W., and Wahl, S. (2015), The impact of mean state errors on equatorial Atlantic interannual variability in a climate model, $\mathrm{J}$. Geophys. Res. Oceans, 120, 1133-1151, doi:10.1002/2014JC010384.

464

39. Chang, P., Zhang, R., Hazeleger, W. et al. Oceanic link between abrupt changes in the North Atlantic Ocean and the African monsoon. Nature Geosci 1, 444-448 (2008). https://doi.org/10.1038/ngeo218

40. Exarchou, E., Prodhomme, C., Brodeau, L. et al. Origin of the warm eastern tropical Atlantic SST bias in a climate model. Clim Dyn 51, 1819-1840 (2018). https://doi.org/10.1007/s00382-017-3984-3

41. Voldoire, A. et al. 2019, Role of wind stress in driving SST biases in the Tropical Atlantic, Clim. Dyn., DOI:10.1007/s00382-019-04717-0, 53(5), 3481-3504.

42. Park, W., Latif, M. Resolution dependence of CO2-induced Tropical Atlantic sector climate changes. npj Clim Atmos Sci 3, 36 (2020). https://doi.org/10.1038/s41612-020-00139-6 El Niño. Nat. Geosci. 3, 391-397 (2010). tropical Pacific response to global warming: a tug of war between the Ocean 
488 understanding model differences in fast and slow tropical Pacific responses to global

489 warming. Clim. Dyn. https://doi.org/10.1007/s00382-021-05818-5 (2021).

490

46. Reynolds RW et al. (2007) Daily high-resolution-blended analyses for sea surface temperature. J Clim 20(22):5473-5496

493

47. Balmaseda, M.A., Mogensen, K. and Weaver, A.T. (2013) Evaluation of the

495 ECMWF ocean reanalysis system ORAS4. Quarterly Journal of the Royal 496 Meteorological Society, 139, 1132-1161.

48. Dee, D. P., et al. 2011: The ERA-Interim reanalysis: configuration and 597. 


\section{Supplementary material}

529

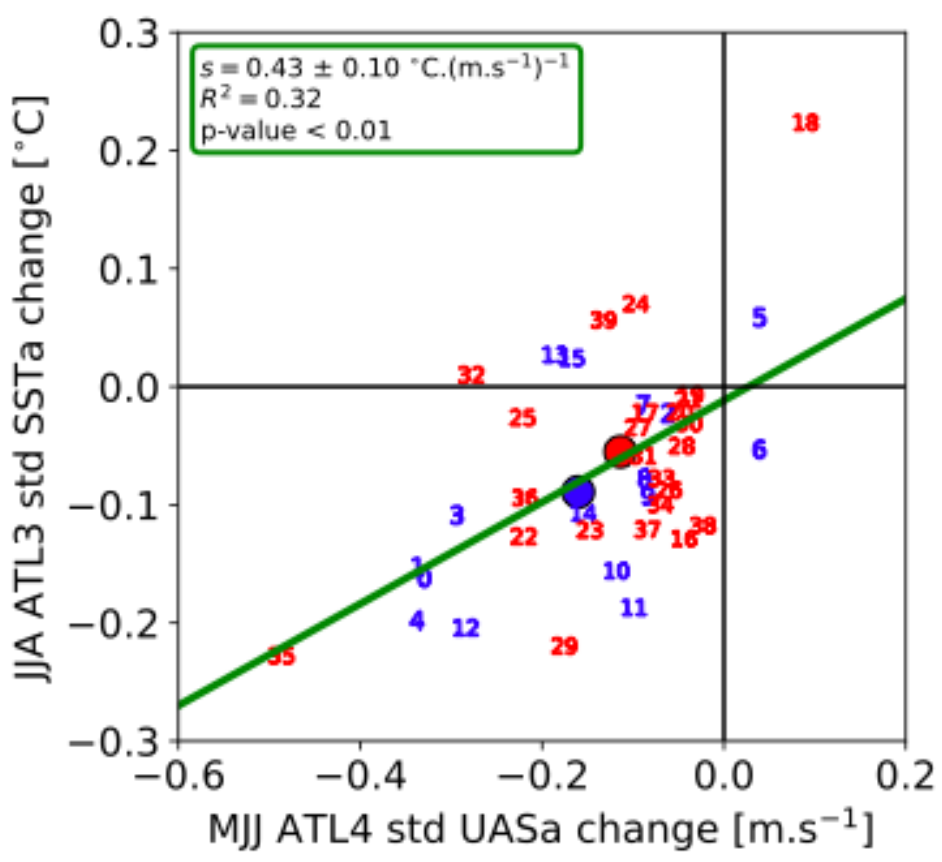

530

Figure S1. Linear regression between the change of the ATL3-averaged JJA SST variability and the change in ATL4-averaged MJJ uas variability. The change is defined as the difference of the mean of the scenario period (2050-99) minus the mean of the historical period (1950-99). CMIP6 (CMIP5) models are presented with blue (red) numbers and the ensemble mean with a circle of the corresponding colour.

536

a)

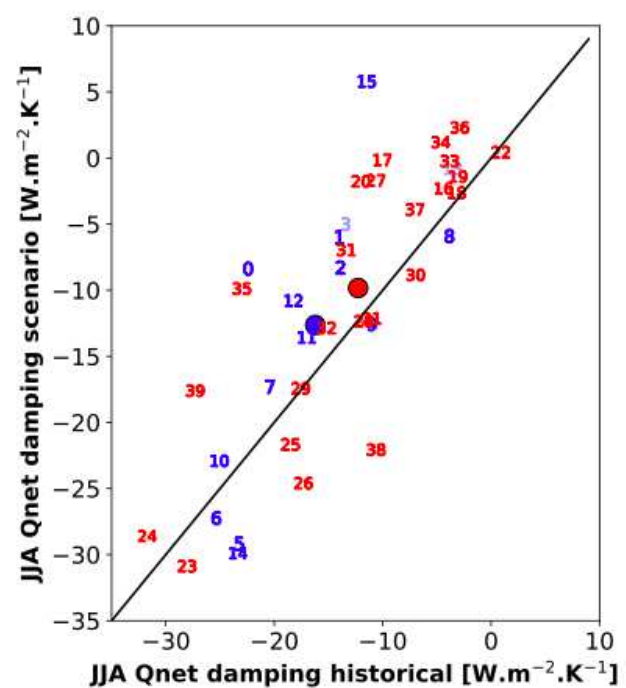

b)

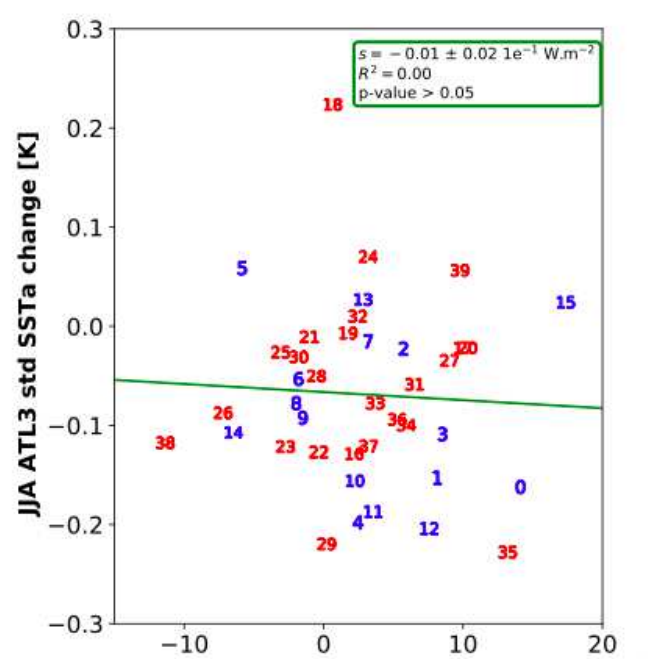

JJA ATL3 Qnet damping change [K.(W. $\left.\left.\mathrm{m}^{-2}\right)^{-1}\right]$

Figure S2. (a) Scatter plot of the ATL3 averaged JJA thermal damping for the historical period (1950-99) in the $x$ axis against the ATL3 averaged JJA thermal damping for the 
540 scenario period (2050-99) in the y axis. Transparent numbers denote the models which 541 exhibit a non significant linear regression for either the historical or future period. The blue 542 and dots represent the ensemble mean of the CMP6 and CMIP5 ensembles, respectively. 543 The black line represents the no-change line and is added for easier interpretation.

544

545

546

547

548 